\title{
Level of Acceptance of COVID-19 Vaccine and Its Determinants among High Risk Groups for Severe COVID-19 Infection Living in Mogadishu Somalia
}

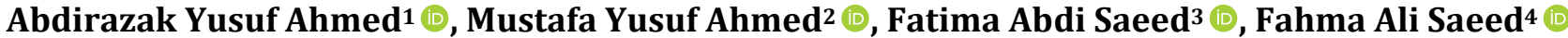 \\ ${ }^{1}$ Ministry of Health Somalia, Demartini Public Hospital, Mogadishu, Somali \\ ${ }^{2}$ Shine Supply Program Action against Hunger, Research Department at Himilo University, Mogadishu, Somali \\ ${ }^{3}$ Mogadishu Medical and Imaging Academy, Mogadishu, Somali \\ ${ }^{4}$ Demartino Public Hospital, Mogadishu, Somali \\ Email: hssadvisor@moh.gov.so,drjalaal@hotmail.com,Dr.mustaf@himilouniversity.edu.so,Dr.Mustapha1993@gmail.com, \\ drsfarido1@gmail.com,fahmaali42@gmail.com
}

How to cite this paper: Ahmed, A.Y., Ahmed, M.Y., Saeed, F.A. and Saeed, F.A. (2021) Level of Acceptance of COVID-19 Vaccine and Its Determinants among High Risk Groups for Severe COVID-19 Infection Living in Mogadishu Somalia. Health, 13, 1206-1221.

https://doi.org/10.4236/health.2021.1311089

Received: August 30, 2021

Accepted: November 9, 2021

Published: November 12, 2021

Copyright $\odot 2021$ by author(s) and Scientific Research Publishing Inc. This work is licensed under the Creative Commons Attribution-NonCommercial International License (CC BY-NC 4.0). http://creativecommons.org/licenses/by-nc/4.0/ (c) (i) (5) Open Access

\section{Abstract}

The severe acute respiratory syndrome coronavirus 2 (SARS-CoV-2) pandemic, which is widely referred to as "COVID-19", has been infecting more than 5.5 million over 144 countries. A vaccine is considered to be the most awaiting intervention and hundreds of global R\&D institutions engaged in unprecedented speed to develop the vaccine. The availability of COVID-19 vaccines may not translate into its uptake. Although governments will provide the vaccines, their uptake is voluntary. Objective: This study was carried out to evaluate the level of acceptance of COVID-19 vaccine and it's determinants among high risk groups for severe COVID-19 infection living in Mogadishu Somalia. Methods: The study was cross-sectional, descriptive analysis conducted to obtain reliable information about the acceptance of COVID19 vaccine and it is determinants among high-risk groups living in Mogadishu, Somalia. The calculated sample size was 404 using Cochran's formula $=$ $\mathrm{Z}^{2} \mathrm{p}(1-\mathrm{p}) / \mathrm{d}^{2}$ and addition of $5 \%$ non-respondent rate. According to PESS population estimate in 2020 , there are 17 districts. We grouped them into 2 strata and through simple random sampling one district was selected from each strata. After randomly selecting the two districts, three sub districts were randomly selected from each and then every second house $(1,3,5)$ in the main roads will be selected. If target population were not found in the second selected house, the next house will be taken until sample size is obtained. Results: $59.4 \%$ of respondents were willing to accept and take vaccination while 
$40.6 \%$ of them were not accepting the vaccination. Being afraid of the side effect was the most common reason for not accepting the vaccine Conclusion: More than one third of respondents (40.6\%) were not willing to accept the vaccination, knowledge towards COVID-19 was strongly associated with acceptance level of COVID-19 vaccine. Recommendation: Multi-sector organized awareness campaigns involving FMH as well as local authorities and civil society to enhance level of knowledge of community towards COVID-19.

\section{Keywords}

COVID-19, Vaccine, Acceptance, High Risk Group, Severe COVID-19

Infection, Knowledge, Comorbidities

\section{Introduction}

\subsection{Background}

The severe acute respiratory syndrome coronavirus 2 (SARS-CoV-2) pandemic, which is widely referred to as "COVID-19", has been infecting more than 5.5 million over 144 countries [1] [2] [3]. The pandemic poses a significant threat to the public health system, including catastrophic economic consequences around the world [4].

A vaccine is considered to be the most awaiting intervention; numerous studies have shown several factors responsible for vaccine acceptance when a new vaccine is introduced [5]. These include the safety and efficacy of the vaccine, adverse health outcomes, misconceptions about the need for vaccination, lack of trust in the health system, lack of knowledge among the community on vaccinepreventable diseases [6]. Misinformation leading towards vaccine hesitancy could put public health at risk in responding to the current crisis [7].

The availability of COVID-19 vaccines may not translate into its uptake. Although governments will provide the vaccines, their uptake is voluntary [8]. Indeed, several studies have demonstrated that not all health care workers are ready to accept COVID-19 vaccines when made available in their country [8] [9].

In Somalia, an online survey showed about one quarter of respondents may refuse to be vaccinated for COVID-19 when the vaccine eventually becomes available in Somalia [10].

\subsection{Statement Problem}

Countries must come together and avoid the temptation of "vaccine nationalism," because the health of people and the economy will not be safe until everyone, everywhere has access to the tools necessary to end this pandemic [11].

The availability of COVID-19 vaccines may not translate into its uptake. Although governments will provide the vaccines, their uptake is voluntary [12]. In- 
deed, several studies have demonstrated that not all health care workers are ready to accept COVID-19 vaccines when made available in their country [8] [9].

In Somalia, an online survey showed about one quarter of respondents may refuse to be vaccinated for COVID-19 when the vaccine eventually becomes available in Somalia [10].

There is a need for generalized community level data regarding the acceptance level of COVID-19 vaccine as well as it is determinants among high-risk group for sever COVID-19 infection.

\subsection{Objective}

\subsubsection{General Objective}

To assess level of acceptance of COVID-19 vaccine and its determinants among high risk groups for severe COVID-19 infection living in MOGADISHU SOMALIA.

\subsubsection{Specific Objective}

1) To identify the demographic determinants that are associated with level of acceptance of COVID-19 vaccine among high risk groups for severe COVID-19 infection living in MOGADISHU SOMALIA.

2) To determine the level of knowledge of towards COVID-19 vaccine among high risk groups for severe COVID-19 infection living in MOGADISHU SOMALIA.

3) To find-out the level of acceptance of COVID-19 vaccine among high risk groups for severe COVID-19 infection living in MOGADISHU SOMALIA.

\section{Literature Review}

COVID-19 erupted in the City of Wuhan in China around the date 31st December 2019. The situation became critical due to numerous infected cases in the "Huanan Seafood Market" [13].

Since its outbreak in Wuhan province of China in December 2019, the coronavirus pandemic has rapidly spread throughout the world, hampering economic activities, causing changes in the patterns and modes of social interaction, affecting political processes, such as by forcing governments of some countries to postpone election activities, and above all, causing the deaths of millions of people [14].

Although countries have been taking various intervention measures to prevent the rapid spreading of the virus, including travel bans and economic lockdowns, declaring states of emergencies to enforce compulsory wearing of face masks, keeping social/physical distance, prohibition of public gatherings, and closure of schools, community spread together with pandemic fatigue have rendered some of these interventions less effective and the need for vaccines is more evident than ever [15].

A vaccine for COVID-19 should be viewed as a global public good. For this 
reason, public institutions should identify and address any potential gaps and barriers, such as the risk of corruption in distribution and allocation processes, to ensure that populations have equitable access to vaccines [16].

Addressing corruption is a priority in times of crisis. This notion was reinforced in the Statement on Corruption in the Context of COVID-19 issued by the Secretary-General in October 2020 when António Guterres underscored that, "(corruption) is even more damaging in times of crisis-as the world is experiencing now with the COVID-19 pandemic." He also noted that the pandemic is creating new opportunities for corruption [17].

The availability of COVID-19 vaccines may not translate into its uptake. Although governments will provide the vaccines, their uptake is voluntary [8]. Indeed, several studies have demonstrated that not all health care workers are ready to accept COVID-19 vaccines when made available in their country [8] [9]. For example, a study conducted in the Democratic Republic of Congo found that approximately $28 \%$ of health care workers were willing to receive the COVID-19 vaccine if available [18]. Reasons for hesitancy to accept COVID-19 vaccines have been identified to include concerns over vaccine safety and side effects and speed of vaccine development/approval [19].

As vaccines are being distributed around the world, there is a debate on who should receive vaccination first [20]. The US Centers for Disease Control and Prevention (CDC) suggested that frontline healthcare workers and groups that are most at risk, such as those aged 60 and above, and persons with certain medical conditions should be prioritized [21]. This should rapidly decrease hospitalizations and deaths, allowing societies to reopen and regain a sense of normalcy. Albeit aiming for herd immunity, there are reports showing hesitancy in accepting the vaccination.

In Somalia, an online survey showed about one quarter of respondents may refuse to be vaccinated for COVID-19 when the vaccine eventually becomes available in Somalia [10].

\section{Methodology}

\subsection{Study Site and Design}

The study will be conducted in Mogadishu, the capital of Somalia. It is a coastal city in east Africa. It is home to over a 2 million inhabitants according to PESS Somalia population estimate 2020. A cross-sectional analytic study design conducted to obtain reliable information about the acceptance of COVID-19 vaccine and it is determinants among high-risk groups for severe COVID-19 infection.

\subsection{Target Population and Sample Size Calculation}

The target population is all high-risk groups for Severe COVID-19 according to WHO and Somalia Vaccine eligibility guideline (over 50 years and those with medical comorbidities such as Diabetes, hypertension, obstructive or restrictive lung diseases, renal failure, organ transplant HIV and other acquired or conge- 
nital Immunodeficiency syndromes), that are living in Mogadishu Somalia. Since the target population is unknown using Cochran's formula $\left(\mathrm{Z}^{2} \mathrm{p}(1-\mathrm{p}) / \mathrm{d}^{2}\right)$ and addition of 5\% non-respondent rate the calculated the sample size was 404 .

\subsection{Sampling Procedure}

According to PESS population estimate in 2020, there are 17 districts in Mogadishu, which are grouped into two strata and through simple random sampling one district was selected from each strata. After randomly selecting the districts (Hodan and Wadajir) three sub districts were randomly selected from each (Xaawa-taako, Tima cade, Jeneral daa'uud form Wadajir and Kacaan, Taleex and October from Hodan) and then every second house $(1,3,5)$ in the main roads will be selected. If target population were not found in the second selected house, the next house will be taken until sample size is obtained

\subsection{Inclusion Criteria and Data Collection Method}

All high-risk groups for severe COVID-19 infections that are living in Mogadishu who are willing to participate voluntarily in our study are included. Those cannot or denied to participate are excluded.

Structured questioner was utilized and carried out by trained research assistances, with the help and guide of the researcher.

\subsection{Assessment of Level of Acceptance COVID-19 Vaccine}

In the assessment of acceptance of the vaccine, we developed a scoring system in accordance with response of the participants to level of acceptance of COVID-19 vaccine section in the questioner. Respondents with minimum of $60 \%$ score were considered to be accepting and willing to take the vaccination while those with less score percentage were considered to be unwilling to take the vaccination.

\subsection{Data Analysis and Processing}

The raw data was entered to the SPSS program of statistics version 20, in order to analyses data. After data entry, the data was processed and the required information was obtained through the SPSS program. A comparison between the groups was made using the Pearson chi square, a descriptive statistics, association between dependent and independent variables was analyzed by calculating the Odd ratios and $95 \%$ confidence level. The processed information was presented through tables and charts.

\subsection{Ethical Consideration}

Ethical approval for the study was obtained from the researchers and ethics committee of Ministry of health.

\subsubsection{Informed Consent}

To get signed letter of informed consent of the respondent, the researcher assis- 
tances introduced themselves to the participants and the study was explained to the participants on the procedure. They were also informed about the criteria of being selected to participate in the study, procedures to follow and any risks and benefits, which may be, involve during the study. They also being informed about the duration of the study, and they were assured that confidentiality was ensured.

\subsubsection{Anonymity}

In this study, we used identity numbers instead of names in order to protect participant's identity.

\section{Results and Findings}

\subsection{Demographic Characteristics}

Respondents with co-morbidities were the least accounting for $21 \%$ (404) of participants while $79 \%$ (404) of them were over 50 year.

Speaking of gender male participants were only $24.5 \%$ (404) making female to be the majority of respondents $75.5 \%$ (404).

Participants were mostly from Hodan district compared to Wadajir in accordance with their total population and sample proportion.

More than quarter of participants $26.3 \%$ (404) were having an average monthly income of less than $\$ 50$ a month while only $38.2 \%$ (404) of them were having an average income of more $\$ 150$ a month.

According to level of education, more than one third of participants $39.3 \%$ (404) had only informal education while only $1 \%$ (404) of respondents were postgraduates.

Speaking of living condition majority of participants were living with their family $97 \%$ (404) leaving only 3\% (404) of participants that were living alone.

The demographic characteristics of respondents are described in Table 1 below.

\subsection{Level of Knowledge towards COVID-19}

$35.6 \%$ (404) of participants think that COVID-19 can't cause death and $24.5 \%$ (404) think it's disease of disbelievers while $60.4 \%$ (404) of them believe that COVID-19 is contagious respiratory disease while only $3.2 \%$ (404) of participants did not have any knowledge about COVID-19.

$21.8 \%$ (404) of respondents think that COVID-19 is not transmittable or contagious disease while majority 78.2\% (404) know that COVID-19 is contagious transmittable respiratory disease.

Among those know that COVID-19 is contagious disease 27.5\% (316) of them think that it's transmitted through fecal-oral route.

Regarding the knowledge towards common symptoms of COVID-19 78.72\% (404) know that it's common symptoms include dry cough, fever, body ache, running nose. 
Table 1. Determines the demographic characteristics of the participants.

\begin{tabular}{|c|c|c|c|}
\hline Variables & & Frequency & Percentage \\
\hline \multirow{3}{*}{ High risk group } & Over 50 years & 319 & $79 \%(404)$ \\
\hline & Co-morbidities & 85 & $21 \%(404)$ \\
\hline & Total & 404 & $100 \%(404)$ \\
\hline \multirow{3}{*}{ Gender } & Male & 99 & $24.5 \%(404)$ \\
\hline & Female & 305 & $75.5 \%(404)$ \\
\hline & Total & 404 & $100 \%(404)$ \\
\hline \multirow{3}{*}{ District } & Hodan & 247 & $61.1 \%(404)$ \\
\hline & Wadajir & 157 & $38.9 \%(404)$ \\
\hline & Total & 404 & $100 \%(404)$ \\
\hline \multirow{5}{*}{ Marital Status } & Single & 22 & $5.4 \%(404)$ \\
\hline & Married & 260 & $64.4 \%(404)$ \\
\hline & Divorced & 95 & $23.5 \%(404)$ \\
\hline & Widowed & 27 & $6.7 \%(404)$ \\
\hline & Total & 404 & $100 \%(404)$ \\
\hline \multirow{4}{*}{ Average Monthly income } & $<\$ 50$ & 149 & $26.3 \%(404)$ \\
\hline & $>\$ 50-150$ & 178 & $35.5 \%(404)$ \\
\hline & $>\$ 150$ & 77 & $38.2 \%(404)$ \\
\hline & Total & 404 & $100 \%(404)$ \\
\hline \multirow{3}{*}{ Living condition } & Alone & 12 & $3 \%(404)$ \\
\hline & With family & 392 & $97 \%(404)$ \\
\hline & Total & 404 & $100 \%(404)$ \\
\hline \multirow{3}{*}{ Employment status } & Un employed & 289 & $71.5 \%(404)$ \\
\hline & Employed & 115 & $28.5 \%(404)$ \\
\hline & Total & 404 & $100 \%$ \\
\hline \multirow{6}{*}{ Level of education } & Informal & 159 & 39.3 \\
\hline & Primary & 124 & 30.7 \\
\hline & Secondary & 88 & 21.8 \\
\hline & University & 29 & 7.2 \\
\hline & Postgraduate & 4 & $1 \%$ \\
\hline & Total & & \\
\hline
\end{tabular}

More than one third of respondents think that COVID-19 is not vaccine preventable disease $45.8 \%$ (404) while $52.8 \%$ of them know that COVID-19 is vaccine preventable disease. 
In assessing the level of knowledge of respondents towards COVID-19 response of the participants with their percentage is described in Table 2.

\section{Score of knowledge}

In the assessment of knowledge, seven questions were utilized. Participants who give the correct answer to minimum of 6 question were considered to having Good knowledge while those who get the correct response in 4 to 6 of the questions are having average knowledge and those with less than or equal to 3 questions were considered to be having poor knowledge towards COVID-19.

Table 2. Describes the level of knowledge towards COVID-19.

\begin{tabular}{|c|c|c|}
\hline Knowledge towards COVID-19 & Frequency & $(\%)$ \\
\hline \multicolumn{3}{|l|}{ COVID-19 is } \\
\hline Disease of disbelievers & 99 & $24.5 \%(404)$ \\
\hline Contagious respiratory disease & 244 & $60.4 \%(404)$ \\
\hline Disease caused by the evil & 48 & $11.9 \%(404)$ \\
\hline I don't know & 13 & $3.2 \%(404)$ \\
\hline \multicolumn{3}{|l|}{ COVID-19 can cause death } \\
\hline Yes & 246 & $60.9 \%(404)$ \\
\hline No & 144 & $35.6 \%(404)$ \\
\hline I don't know & 14 & $3.5 \%(404)$ \\
\hline \multicolumn{3}{|l|}{ COVID-19 is transmittable } \\
\hline Yes & 316 & $78.2 \%(404)$ \\
\hline No & 88 & $21.8 \%(404)$ \\
\hline \multicolumn{3}{|l|}{ If yes it's transmitted trough } \\
\hline Respiratory droplets or contacts with infected surface & 217 & $68.7 \%(404)$ \\
\hline Fecal-oral route & 87 & $27.5 \%(404)$ \\
\hline I do not know & 12 & $3.8 \%(404)$ \\
\hline \multicolumn{3}{|l|}{ COVID-19 is manageable } \\
\hline Yes & 268 & $66.3 \%(404)$ \\
\hline No & 136 & $33.7 \%(404)$ \\
\hline \multicolumn{3}{|l|}{ Common symptoms of COVID-19 } \\
\hline Dry cough, fever, body ache, running nose & 318 & $78.72 \%(404)$ \\
\hline Diarrhea, Vomiting, and loss of appetite & 85 & $21.04 \%(404)$ \\
\hline I do not know & 1 & $0.24 \%(404)$ \\
\hline \multicolumn{3}{|l|}{ COVID-19 is vaccine preventable } \\
\hline Yes & 219 & $54.2 \%(404)$ \\
\hline No & 185 & $45.8 \%(404)$ \\
\hline
\end{tabular}


Respondents with good knowledge towards COVID-19 were the least among the participants accounting for only $25.7 \%$ (404) while majority $43.6 \%$ (404) had average knowledge regarding COVID-19.

Figure 1 presents the score of knowledge towards COVID-19 among respondents.

\subsection{Level of Acceptance of COVID-19 Vaccine}

In the assessment of Acceptance of COVID-19 vaccine three questions were utilized with different scoring. The right answer to the last question gives the participants a score of 60 points while the remaining two give 20 points each, the last question determines where the respondent is ready to take the vaccine and the first two will measure how ready for.

Only $24.5 \%$ of participants were willing to even pay to get vaccinated against COVID-19 and 27\% (404) were ready to look for vaccine if told that there might COVID-19 Vaccine available in the country.

Only 59.4\% (404) of participants were accepting and willing to take the vaccine while $40.6 \%$ (404) of them were not the vaccine at all.

Over half of those that are not accepting the vaccine $52.4 \%$ (164) were doing so because they were afraid of the side effects while $18.9 \%$ of them believed that the vaccine is ineffective.

Assessment of level of accepting of COVID-19 vaccine is described in Table 3.

Reasons for not accepting the vaccine were formulated using literature articles as well as pilot test to acquire the most common reasons for not accepting the vaccine.

\section{Bivariate analysis}

In this, section the association between the determinant factors and the acceptance of COVID-19 vaccine was evaluated.

A chi square test showed that there is no statistically significant association between risk group and the level of acceptance of COVID-19 vaccine since the $P$ value is greater than $0.05(0.756)$.

While in the assessment of monthly income a chi square test shows there is a strong statistical significant association between average monthly income and

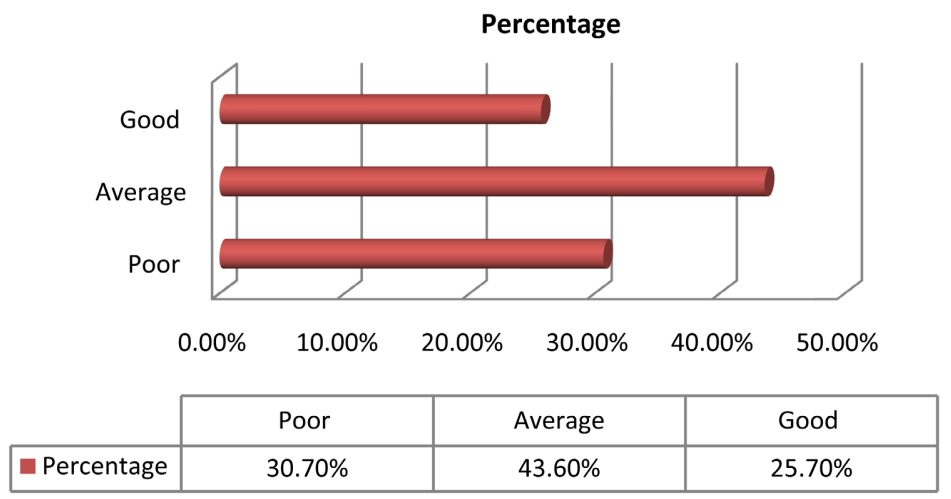

Figure 1. Describes score of knowledge towards COVID-19. 
Table 3. Demonstrates level of acceptance of COVID-19 vaccine.

\begin{tabular}{|c|c|c|}
\hline Level of Acceptance of COVID-19 vaccine & Frequency & $(\%)$ \\
\hline \multicolumn{3}{|l|}{ Would you pay to get vaccinated against COVID-19 } \\
\hline Yes & 43 & $24.5 \%(404)$ \\
\hline No & 361 & $60.4 \%(404)$ \\
\hline \multicolumn{3}{|l|}{ If you were told that there might COVID-19 } \\
\hline \multicolumn{3}{|l|}{ Vaccine available in the country would you look for it } \\
\hline Yes & 109 & $27 \%(404)$ \\
\hline No & 295 & $73 \%(404)$ \\
\hline \multicolumn{3}{|l|}{ Would you take COVID-19 } \\
\hline \multicolumn{3}{|l|}{ Vaccine if made available to you } \\
\hline Yes & 240 & $59.4 \%(404)$ \\
\hline No & 114 & $28.2 \%(404)$ \\
\hline Maybe & 50 & $12.4 \%(404)$ \\
\hline \multicolumn{3}{|l|}{ If no why } \\
\hline I don't believe in vaccinations & 47 & $28.7 \%(404)$ \\
\hline Afraid of side effect & 86 & $52.4 \%(404)$ \\
\hline Being ineffective & 31 & $18.9 \%(404)$ \\
\hline \multicolumn{3}{|l|}{ Score of Acceptance } \\
\hline$\geq 60 \%$ (Accepting and willing) & 240 & $59.4 \%(404)$ \\
\hline$<60 \%$ Not accepting at all & 164 & $40.6 \%(404)$ \\
\hline
\end{tabular}

the level of acceptance of COVID-19 vaccine since the $\mathrm{P}$ value is less than 0.05 (0.01). Respondents with average monthly income of less than $\$ 50$ are 5.6321 times more likely to not accept the vaccination with a confidence level of $95 \%$.

In the assessment of association test between score of knowledge towards COVID-19 chi square test shows that there is a strong statistical significant association between the score of knowledge and level of acceptance of COVID-19 vaccine with a $\mathrm{P}$ value of less than $0.05(0.0002)$. The respondents with good knowledge score, were 12.69 times more likely to accept the vaccination with a confidence level of $95 \%$.

Table 4 details the bivariate association between the variable with the significance level of the association.

\section{Discussion}

Despite the free delivery of COVID-19 vaccine the level of Acceptance and willing to take the vaccine is low since almost half $(40.6 \%)$ of participants were not accepting or willing to take the vaccine while $59.4 \%$ (404) of them were accepting and willing to take the vaccine. 
Table 4. Details the association test between the determinants and level of acceptance.

\begin{tabular}{|c|c|c|}
\hline \multirow{2}{*}{$\begin{array}{l}\text { Determinants of level of acceptance } \\
\text { of COVID-19 vaccine }\end{array}$} & \multicolumn{2}{|c|}{ Association test } \\
\hline & $\begin{array}{l}\text { Sig or } \\
\text { P-value }\end{array}$ & $\begin{array}{c}\text { Chi } \\
\text { square }\end{array}$ \\
\hline High risk group & 0.756 & 1.36 \\
\hline \multicolumn{3}{|l|}{ Over 50 years } \\
\hline \multicolumn{3}{|l|}{ Co-Morbidities } \\
\hline Gender: Female to male & 0.187 & 4.162 \\
\hline District & 0.943 & 0.8765 \\
\hline \multicolumn{3}{|l|}{ Hodan } \\
\hline \multicolumn{3}{|l|}{ Wadajir } \\
\hline Marital status: & 1.006 & \\
\hline \multicolumn{3}{|l|}{ Single } \\
\hline \multicolumn{3}{|l|}{ Married } \\
\hline \multicolumn{3}{|l|}{ Divorced } \\
\hline \multicolumn{3}{|l|}{ Widowed } \\
\hline Average monthly income & 0.01 & 5.6321 \\
\hline \multicolumn{3}{|l|}{$<\$ 50$} \\
\hline \multicolumn{3}{|l|}{$\$ 50-\$ 150$} \\
\hline \multicolumn{3}{|l|}{$>\$ 150$} \\
\hline Living condition & 0.670 & 1.4352 \\
\hline \multicolumn{3}{|l|}{ Alone } \\
\hline \multicolumn{3}{|l|}{ With family } \\
\hline Level of education & 0.006 & 3.691 \\
\hline \multicolumn{3}{|l|}{ Informal } \\
\hline \multicolumn{3}{|l|}{ Primary education } \\
\hline \multicolumn{3}{|l|}{ Secondary education } \\
\hline \multicolumn{3}{|l|}{ University level } \\
\hline \multicolumn{3}{|l|}{ Postgraduate } \\
\hline Employment & 0.0892 & 2.07 \\
\hline \multicolumn{3}{|l|}{ Employed } \\
\hline \multicolumn{3}{|l|}{ Un employed } \\
\hline Score of Knowledge: & 0.0002 & 12.69 \\
\hline \multicolumn{3}{|l|}{ Good } \\
\hline \multicolumn{3}{|l|}{ Average } \\
\hline poor & & \\
\hline
\end{tabular}


In Contrast to our study finding an online survey conducted through social media showed about one quarter of respondents may refuse to be vaccinated for COVID-19 when the vaccine eventually becomes available in Somalia [10].

This is much less than our findings in level of acceptance of COVID-19 vaccine, since our data was community based and the online survey was conducted through snowballing using social media platforms in which university level students were their most participants.

The most common reasons for not accepting the vaccine was being afraid of the side effect which emphasis the effect of misleading information regarding the vaccine.

A study conducted in the Democratic Republic of Congo found that approximately $28 \%$ of health care workers were willing to receive the COVID-19 vaccine if available [8] [9]. Reasons for hesitancy to accept COVID-19 vaccines have been identified to include concerns over vaccine safety and side effects and speed of vaccine development/approval [11].

In the evaluation of the determinants of level of acceptance of the vaccine and association with acceptance level a chi square test showed that score of knowledge towards COVID-19 has the strongest statically association with level of acceptance of COVID-19. Furthermore as shown in the univariate section only $25.7 \%$ of participants had good level of knowledge of towards COVID-19. After the assessment we introduce the right knowledge of COVID-19 to the participants which had boosting effect on their accepting level of COVID-19 vaccine suggesting a strong association between knowledge towards COVID-19 and Acceptance of the vaccine as just like the statically analysis shown.

The struggle to survive or low monthly income have shown to have significant association with level of accepting if COVID-19 vaccine since respondents with average monthly income of less than $\$ 50$ are 5.6321 times more likely to not accept the vaccination.

\section{Conclusions}

Almost half of respondents were not accepting or willing to take COVID-19 vaccine, being afraid of the side effects was the most common reason followed by not believing in the vaccines at all.

Knowledge towards COVID-19, average monthly income and level of education were shown to have significant association with level of acceptance of COVID-19 vaccine among respondents.

\section{Recommendation}

1) Multi-sector organized awareness campaigns involving FMH as well as local authorities and civil society to enhance level of knowledge of community towards COVID-19.

2) Dissemination of scientific based information regarding the COVID-19 vaccine to overcome the miss leading and biased information about the vaccine that 
is widely spread and misleading the community.

3) Easily accessible vaccine distribution with technical and logistic responsibility and accountability to ensure safe and accessible vaccine delivery. This will certainly help the low-income sociality to have easy access vaccine.

4) More in-depth investigation as well broader geographic area with qualitative data to find-out the factors behind the low acceptance level of COVID-19 vaccine.

\section{Conflicts of Interest}

The authors declare no conflicts of interest regarding the publication of this paper.

\section{References}

[1] Chakraborty, C., Sharma, A.R., Sharma, G., Bhattacharya, M. and Lee, S.S. (2020) SARS-CoV-2 Causing Pneumonia-Associated Respiratory Disorder (COVID-19): Diagnostic and Proposed Therapeutic Options. European Review for Medical and Pharmacological Sciences, 24, 4016-4026.

[2] Saha, R.P., Sharma, A.R., Singh, M.K., et al. (2020) Repurposing Drugs, Ongoing Vaccine, and New Therapeutic Development Initiatives against COVID-19. Frontiers in Pharmacology, 11, 1258. https://doi.org/10.3389/fphar.2020.01258

[3] Chakraborty, C., Sharma, A.R., Bhattacharya, M., Sharma, G. and Lee, S.S. (2020) The 2019 Novel Coronavirus Disease (COVID-19) Pandemic: A Zoonotic Prospective. Asian Pacific Journal of Tropical Medicine, 13, 242. https://doi.org/10.4103/1995-7645.281613

[4] Chakraborty, C., Sharma, A.R., Sharma, G., Bhattacharya, M., Saha, R.P. and Lee, S.-S. (2020) Extensive Partnership, Collaboration, and Teamwork Is Required to Stop the COVID-19 Outbreak. Archives of Medical Research, 51, 728-730. https://doi.org/10.1016/j.arcmed.2020.05.021

[5] Bhattacharya, M., Sharma, A.R., Patra, P., et al. (2020) Development of EpitopeBased Peptide Vaccine against Novel Coronavirus 2019 (SARS-COV-2): Immunoinformatics Approach. Journal of Medical Virology, 92, 618-631. https://doi.org/10.1002/jmv.25736

[6] Wu, S., Su, J., Yang, P., et al. (2018) Willingness to Accept a Future Influenza A (H7N9) Vaccine in Beijing, China. Vaccine, 36, 491-497. https://doi.org/10.1016/j.vaccine.2017.12.008

[7] Larson, H.J., Jarrett, C., Eckersberger, E., Smith, D.M.D. and Paterson, P. (2014) Understanding Vaccine Hesitancy around Vaccines and Vaccination from a Global Perspective: A Systematic Review of Published Literature, 2007-2012. Vaccine, 32, 2150-2159. https://doi.org/10.1016/j.vaccine.2014.01.081

[8] Nzaji, M.K., Ngombe, L.K., Mwamba, G.N., et al. (2020) Acceptability of Vaccination against COVID-19 among Healthcare Workers in the Democratic Republic of the Congo. Pragmatic and Observational Research, 11, 103-109. https://doi.org/10.2147/POR.S271096

[9] Shaw, J., Stewart, T. anderson, K.B., et al. (2021) Assessment of US Health Care Personnel (HCP) Attitudes towards COVID-19 Vaccination in a Large University Health Care System. Clinical Infectious Diseases.

https://doi.org/10.1093/cid/ciab054 
[10] Ahmed, M.A.M., et al. (2021) COVID-19 Vaccine Acceptability and Adherence to Preventive Measures in Somalia: Results of an Online Survey. https://doi.org/10.3390/vaccines 9060543

[11] Shekhar, R., Sheikh, A.B., Upadhyay, S., et al. (2021) COVID-19 Vaccine Acceptance among Health Care Workers in the United States. Vaccines, 9, 119. https://doi.org/10.3390/vaccines 9020119

[12] Persad, G., Peek, M.E. and Emanuel, E.J. (2020) Fairly Prioritizing Groups for Access to COVID-19 Vaccines. JAMA, 324, 1601-1602. https://doi.org/10.1001/jama.2020.18513

[13] Dooling, K., McClung, N., Chamberland, M., Marin, M., Wallace, M., Bell, B.P., Lee, G.M., Talbot, H.K., Romero, J.R. and Oliver, S.E. (2020) The Advisory Committee on Immunization Practices' Interim Recommendation for Allocating Initial Supplies of COVID-19 Vaccine-United States, 2020. Morbidity and Mortality Weekly Report, 69, 1857. https://doi.org/10.15585/mmwr.mm6949e1

[14] Dror, A.A., Eisenbach, N., Taiber, S., Morozov, N.G., Mizrachi, M., Zigron, A., Srouji, S. and Sela, E. (2020) Vaccine Hesitancy: The Next Challenge in the Fight against COVID-19. European Journal of Epidemiology, 35, 775-779. https://doi.org/10.1007/s10654-020-00671-y

[15] Hacquin, A.S., Altay, S., de Araujo, E., Chevallier, C. and Mercier, H. (2020) Sharp Rise in Vaccine Hesitancy in a Large and Representative Sample of the French Population: Reasons for Vaccine Hesitancy.

[16] Latkin, C.A., Dayton, L., Yi, G., Colon, B. and Kong, X. (2021) Mask Usage, Social Distancing, Racial, and Gender Correlates of COVID-19 Vaccine Intentions among Adults in the US. PLoS ONE, 16, e0246970. https://doi.org/10.1371/journal.pone.0246970

[17] Murphy, J., Vallières, F., Bentall, R.P., Shevlin, M., McBride, O., Hartman, T.K., McKay, R., Bennett, K., Mason, L., Gibson-Miller, J., et al. (2021) Psychological Characteristics Associated with COVID-19 Vaccine Hesitancy and Resistance in Ireland and the United Kingdom. Nature Communications, 12, 29. https://doi.org/10.1038/s41467-020-20226-9

[18] Flanagan, K.L., Fink, A.L., Plebanski, M. and Klein, S.L. (2017) Sex and Gender Differences in the Outcomes of Vaccination over the Life Course. Annual Review of Cell and Developmental Biology, 33, 577-599. https://doi.org/10.1146/annurev-cellbio-100616-060718

[19] He, J. and He, L. (2018) Knowledge of HPV and Acceptability of HPV Vaccine among Women in Western China: A Cross-Sectional Survey. BMC Women's Health, 18, 130. https://doi.org/10.1186/s12905-018-0619-8

[20] Yeung, M.P., Lam, F.L. and Coker, R. (2016) Factors Associated with the Uptake of Seasonal Influenza Vaccination in Adults: A Systematic Review. Journal of Public Health, 38, 746-753. https://doi.org/10.1093/pubmed/fdv194

[21] Jarrett, C., Wilson, R., O’Leary, M., Eckersberger, E. and Larson, H.J. (2015) Strategies for Addressing Vaccine Hesitancy-A Systematic Review. Vaccine, 33, 4180 4190. https://doi.org/10.1016/j.vaccine.2015.04.040 


\section{Questioner}

This research is meant for purely academic purposes. You are kindly requested to provide answers to these questions as honestly and precisely as possible. Responses to these questions will be treating as confidential

\begin{tabular}{|c|c|c|}
\hline \multicolumn{2}{|c|}{ Demographic characteristics } & Tick $\sqrt{ }$ \\
\hline \multirow{2}{*}{ High-risk group } & Over 50 years & \\
\hline & Under lying medical condition & \\
\hline \multirow{2}{*}{ Gender } & Male & \\
\hline & Female & \\
\hline \multirow{2}{*}{ District } & Wadajir & \\
\hline & Hodan & \\
\hline \multirow{4}{*}{ Marital Status } & Single & \\
\hline & Married & \\
\hline & Divorced & \\
\hline & Widowed & \\
\hline \multirow{3}{*}{ Average Monthly income } & $<\$ 50$ & \\
\hline & $>\$ 50-150$ & \\
\hline & $>\$ 150$ & \\
\hline \multirow{2}{*}{ Living condition } & Alone & \\
\hline & With family & \\
\hline \multirow{5}{*}{ Level of education } & Informal & \\
\hline & Primary Education & \\
\hline & Secondary Education & \\
\hline & University level & \\
\hline & Postgraduate & \\
\hline \multirow{2}{*}{ Employment status } & Un employed & \\
\hline & Employed & \\
\hline \multicolumn{2}{|c|}{ Knowledge towards COVID-19 } & Tick $\sqrt{ }$ \\
\hline
\end{tabular}

Never heard before

Ever heard of COVID-19 Heard from the news and social media

Read or learnt about it

Disease of disbelievers

What is COVID-19

Contagious respiratory disease

Disease caused by the evil

I don't know 


\section{Continued}

\begin{tabular}{cc}
\hline $\begin{array}{c}\text { COVID-19 is serious } \\
\text { disease that can lead to death }\end{array}$ & Yes \\
& No \\
I don't know \\
COVID-19 can spread \\
from one person to another & Yes \\
& No \\
If Yes COVID-19 is & I don't know \\
transmitted through & Blood transfusion \\
& Respiratory droplets \\
(coughing and sneezing) & I don't know \\
COVID is un & Yes \\
manageable condition & No \\
& I don't know
\end{tabular}

Dry cough and fever

Productive cough without fever

Sign and symptoms

of COVID-19 include

Abdominal pain

Body ache and lose of test and smell

I don't know

Yes

COVID-19 is Vaccine

preventable disease

No

I don't know

\begin{tabular}{|c|c|c|}
\hline \multicolumn{2}{|c|}{ Level of Acceptance of COVID-19 Vaccine } & \multirow[t]{3}{*}{ Tick $\sqrt{ }$} \\
\hline Would you pay to get vaccinated & Yes & \\
\hline against COVID-19 & No & \\
\hline If you were told that there might & Yes & \\
\hline COVID-19 Vaccine available & No & \\
\hline in the country would you look for it & Maybe & \\
\hline Would you take COVID-19 & Yes & \\
\hline Vaccine if made available to you & No & \\
\hline
\end{tabular}

I don't believe in vaccinations

If no why

Afraid of side effect

Being ineffective

Good

Score of Acceptance

Average

Not Accepting at all 